\title{
Performance Analysis of AODV on the Basis of Network Survivability over MANET using NS2
}

\author{
Jitender Grover ${ }^{1}$, Anjali $^{2}$ and Anshul ${ }^{3}$ \\ ${ }^{1,2,3}$ (Assistant Professor, Computer Science \& Engineering Department, MM University, Sadopur, Ambala, \\ India) \\ 1jitendergrover0101@gmail.com, ${ }^{2}$ anjaligrover2202@gmail.com, ${ }^{3}$ anshul0407@gmail.com
}

\begin{abstract}
In Mobile Ad-Hoc Networks (MANETs), mobile devices are equipped with power (energy). In order to utilize this energy equipped devices efficiently for transmission of data packets, many energy aware routing strategies are followed. Effective transmission power control is a critical issue in the design and performance of wireless ad hoc networks. Transmission Power affects the Survivability of the Network. Today, the design of packet radios and protocols for wireless ad hoc networks are primarily based on common-range transmission control. Mobility speed of the nodes and extension of ad hoc network affects the performance as well. In this paper, one of the widely used routing protocol AODV with varying transmission range, mobility speed and number of nodes is analyzed. Data transmitted by a node is received by all the nodes within its communication range. This paper focuses on the analysis of varying the range of the transmission in terms of distance, mobility speed and number of nodes in the network. The proposed work has been simulated using NS2.34.The performance metrics comprises of Network Survivability has been analyzed in this paper.
\end{abstract}

Keywords - MANET, Network Survivability, Transmission Range, NS 2.34

\section{INTRODUCTION}

Mobile ad hoc networks (MANETs) are rapidly evolving as an important area of mobile mobility. MANETs are infrastructure less and wireless in which there are several routers which are free to move arbitrarily and can manage themselves in same manners. Now-a-days mobile ad hoc networks have robust and efficient operation in mobile wireless networks as it can include routing functionality into mobile nodes which is more than just mobile hosts and reduces the routing overhead and saves energy for other nodes [21]. In Latin, ad-hoc means "for this," further meaning "for this purpose only. It is a good and emblematic description of the idea why ad hoc networks are needed. They can be set up anywhere without any need for external infrastructure (like wires or base stations) [22][23].

An ad-hoc network is a LAN or other small network, especially one with wireless connections, in which some of the network devices are part of the network only for the duration of a communications session or, in the case of mobile or portable devices, while in some close proximity to the rest of the network [5][13]. Recently, an increasing number of wirelesses local area network (LAN) hot spots are emerging, allowing travelers with portable computers to surf the Internet from airports, railways, hotels and other public locations [6][14]. Non-infrastructure-based MANET is expected to become an important part of the $4 \mathrm{G}$ architecture. An ad hoc mobile network is a transient network formed dynamically by a collection of (arbitrarily located) wireless mobile nodes without the use of existing network infrastructure, or centralized administration[24][15]. Ad hoc networks are created, for example, when a group of people come together, and use wireless communications for some computer-based collaborative activities; this is also referred to as spontaneous networking [7][16].

\section{RELATED WORK}

Authors in [1] gives a survey on recently proposed reactive routing protocols in mobile ad hoc networks (MANETs) which are based on Neighbour knowledge method and load balancing approach. Broadcasting mechanism is used to discover a route. Neighbour knowledge broadcasting technique is used to reduce retransmissions, collision and contention in network. Load balancing approach is used to distribute load of central network. Authors has been focused on performance metric for comparing the performance of routing 
protocols. Performance metrics are Packet Delivery Ratio, End-To-End Delay, and Normalized Routing Overhead.

In paper [2], authors proposed new intelligent algorithm (SG-AODV) for routing to improve AODV routing protocol. In this algorithm, scores are considered for nodes according to energy of nodes, congestion in the routing queue of nodes and link states. Algorithm uses scores for selecting best rout and chooses rout with highest score as main route and rest of discovered routs are stored in temporal memory or cache of nodes to use them if main route is damaged or interrupted. Results show that this algorithm improves the delay of sent packets, routing overhead and delivered packets of AODV protocol.

Authors in [3] examines the impact of the different mobility properties on the performance of selforganizing networks. One of the most challenging requirements in cutting-edge Mobile Ad hoc Networks is the need for adaptive and efficient routing. Networks capable of adapting their behavior based on current conditions are often characterized as self-organizing networks, which are lately considered very promising for future applications. Particularly, this paper focuses on the effect of the different mobility schemes on network topology and consequently to the overall network performance. The results reveal the tight correlations between node mobility characteristics and network metrics.

For efficient data transmission in adhoc network, it is critical to understand the type of routing algorithms that is being used by these networks. In paper[4], authors make a comprehensive performance analysis of the various ad-hoc routing protocols, simulate them under various scenarios, analyze some important performance parameters to examine which routing protocol can be deemed efficient in what type of scenarios. This paper is divided into three different phases to make comprehensive analysis of the mobile ad-hoc routing protocols by varying mobility, speed and network load. Simulations results suggest that DSR should be the first preference in terms of small scale networks with various spend or mobility pattern. AODV or OLSR should be considered when the load of the network is increased.

In [25], the performance and comparison of different routing protocols of Mobile ad hoc networks based on the energy level are discussed. To reduce the energy consumption in AODV, DSR, proposed enhanced AODV and enhanced DSR. Simulations are done using NS-2 and the results show that enhanced AODV and enhanced DSR consumes less energy compared to existing protocols and also comparison of energy consumption in each protocol. Results show that AODV performs better than DSR in terms of energy consumption.

Authors in [26] compared the performance of AODV and DSDV on the basis of consumer energy and other traditional metrics using NS 2.34 simulator with varying number of nodes and fixed mobility speed. In this paper result shows that AODV performs better than DSDV in terms of energy consumption and Packet Delivery Fraction. Performance analysis of AODV on different mobility speeds with varying number of connections has been done in [27] using NS2 as simulator. Simulation results show that AODV performs better in increasing mobility and traffic load.

The effect of power variations on AODV using Matlab based Timeline simulator is shown in [28]. Simulation results show that performance of AODV increases with increase in power. The performance of AODV and DSR on the basis of residual energy and other performance metrics has been evaluated in [29] using NS2 simulator with increasing number of nodes. Analysis shows that on the basis of Energy consumption and throughput DSR performs better than AODV.

In [30], Energy consumption performance of AODV, DSR, TORA and DSDV protocols under the different mobility models like Random Waypoint, RPGM and Manhattan Grid with different mobility speeds using Ns2 simulator. Simulation result shows that in low speed environment DSR is generally best out of all but in highly Dynamic environment Pro-active protocols save more power. In [31], analysis of DSR, AODV, DSDV, TORA, FSR, CBRP and CGSR has been done on the basis of consumed energy using NS2 simulator. Analysis result shows that DSR and AODV protocols perform better than other protocols.

The authors in [32] compares the performance of AODV, DSDV and DSR routing protocols in grid environment by varying pause time to show the impact of mobility on 50 nodes scenario. Their results indicate that AODV outperforms DSR and DSDV. DSR was very good at all mobility rates and movement speeds than DSDV. In [33] the performance of AODV and DSR routing protocols has been observed in group mobility 
model by varying mobility speeds. The result of AODV is better than DSR in CBR traffic and real time delivery of data, but DSR perform better in TCP traffic under restriction of bandwidth.

In [34] on different mobility scenarios the performance comparison of AODV, DSR, OLSR and ZRP in WIMAX environment has been conducted. The simulation result on different QoS metrics shows that AODV, ZRP perform better than DSR and OLSR. The performance of AODV and DSR routing protocols in wireless sensor network with varying load by varying number of sources and mobility speeds on 50 and 100 nodes scenario has been simulated in [35]. Their results indicate AODV perform better than DSR when node density and traffic load is low otherwise DSR delivers good performance. In [36] a simulation based performance comparison of DSDV and DSR routing protocols with variation in number of nodes with fixed transmission range $250 \mathrm{~m}$ has been analyzed and it has observed from their results that DSR outperforms DSDV. A simulation based performance analysis on AODV, TORA, OLSR and DSR routing protocols for voice communication support over hybrid MANETs has been conducted in [37].

\section{OVERVIEW OF ZONE ROUTING PROTOCOLS}

The Routing protocols for MANETs have been classified according to the strategies of discovering and maintaining routes into three classes: proactive, reactive and Hybrid[17].

A. Destination Sequenced Distance Vector (DSDV): DSDV [38] is a proactive or table-driven routing protocol. In DSDV, each node maintains a routing table that has an entry for each destination in the network. The attributes for each destination are the next hop ID, hop count metric and a sequence number which is originated by the destination node. DSDV uses both periodic and triggered routing updates and guarantees loop freedom[8][18]. Upon receiving a route update packet, each node compares it to the existing information regarding the route. Routes with old sequence numbers are simply discarded.

B. Dynamic Source Routing Protocol (DSR): The Dynamic Source Routing (DSR) [39] [40] protocols an ondemand routing protocol based on source routing. In the source routing technique, a sender determines the exact sequence of nodes through which to propagate a packet. The list of intermediate nodes for routing is explicitly contained in the packet's header. In DSR, every mobile node in the network needs to maintain a route cache where it caches source routes that it has learned. When a host wants to send a packet to some other host, it first checks its route cache for a source route to the destination. In the case a route is found, the sender uses this route to propagate the packet[19]]. Otherwise the source node initiates the route discovery process. In route discovery, the source floods a query packet through the ad-hoc network, and the reply is returned by either the destination or another host that can complete the query from its route cache[9][10]. Upon reception of a query packet, if a node has already seen this ID (i.e. it is a duplicate) or if it finds its own address already recorded in the list, it discards the copy and stops flooding; otherwise, it appends its own address to the list and broadcasts the query to its neighbors'. For route maintenance when a route failure is detected the node detecting the failure sends an error packet to the source, which then uses the route discovery protocol to find a new route.

C. Ad hoc On-demand Distance Vector Routing (AODV): The AODV [41] [42] is a reactive protocol, which combines both DSR and DSDV characteristics. AODV borrows the basic route discovery and routemaintenance of DSR as well as hop-by-hop routing, sequence numbers and beacons of DSDV[11][12]. When a source node desires to establish a communication session, it initiates a route discovery process by generating a route request (RREQ) message, which might be replied by the intermediate nodes in the path to destination or the destination node itself with the route reply (RREP) message contains the whole path to destination. Failure of a link can be detected via hello messages. [43][20] Failure to receive three consecutive HELLO messages from a neighbor is taken as an indication that the link to the neighbor in question is down.

\section{SIMULATION RESULTS AND DISCUSSION}

The performance of AODV, DSDV and DSR has been analyzed with varying transmission range, connection type (TCP, UDP), mobility and number of nodes. The parameters used for simulation are summarized in Table 1 and positioning of 75 and 100 nodes is illustrated in Figure 1 and Figure 2. The 
IOSR Journal of Computer Engineering (IOSR-JCE)

e-ISSN: 2278-0661, p-ISSN: 2278-8727

performance metrics comprises of QoS parameters such as packet delivery ratio, end to end delay, routing overhead and throughput.

TABLE I. SIMULATION PARAMETERS

\begin{tabular}{|l|l|}
\hline Parameters & Values \\
\hline No of Node & 75,100 \\
\hline Simulation Time & $10 \mathrm{sec}$ \\
\hline Environment Size & $1200 x 1200$ \\
\hline Traffic Type & $\begin{array}{l}\text { CBR (Constant Bit } \\
\text { Rate) }\end{array}$ \\
\hline Queue Length & 50 \\
\hline Source Node & Node 0 \\
\hline Destination Node & Node 7 \\
\hline Mobility Model & Random Waypoint \\
\hline Antenna Type & Omni Directional \\
\hline Connection Type & TCP, UDP \\
\hline Simulator & NS-2.34 \\
\hline Mobility Speed & $10,20,30$ m/s \\
\hline Transmission Range (in meters) & 400 and 500 \\
\hline Operating System & $\begin{array}{l}\text { Linux Enterprise } \\
\text { Edition-5 }\end{array}$ \\
\hline
\end{tabular}

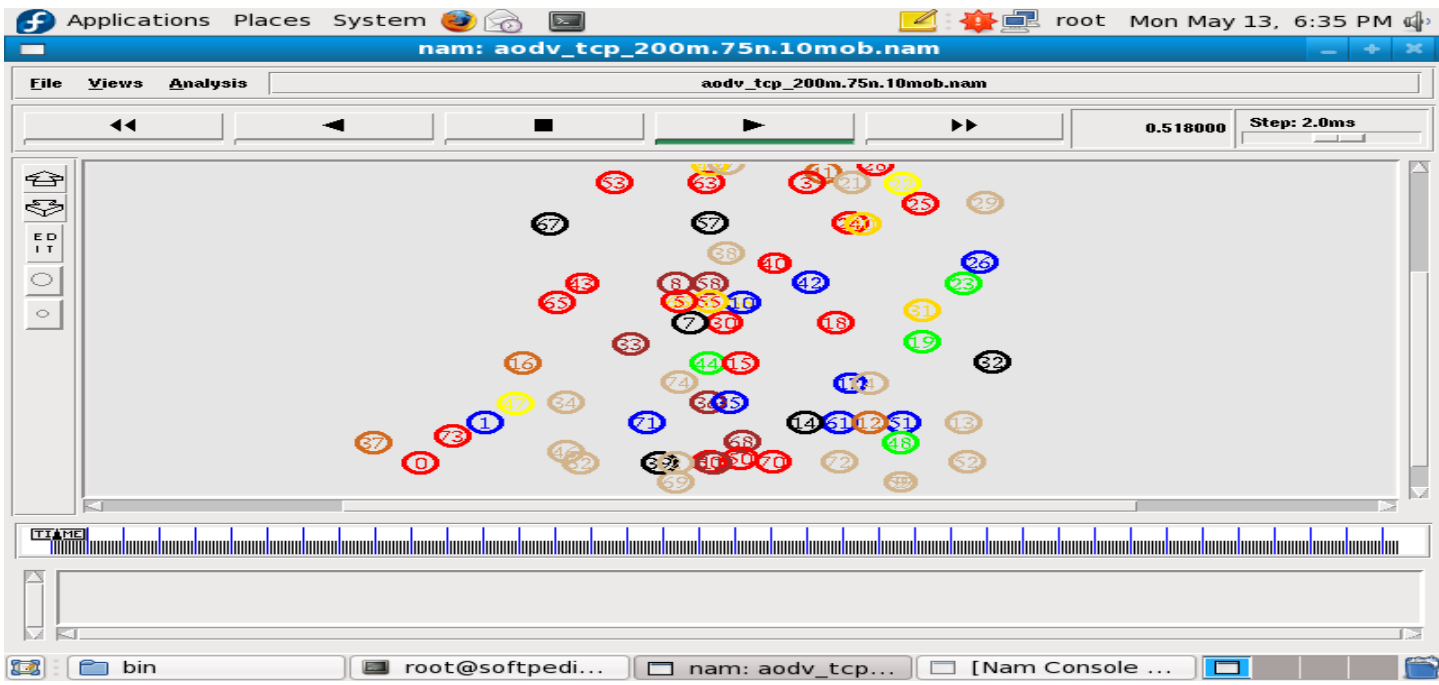

Fig. 1: Initial Positioning of 75 Nodes

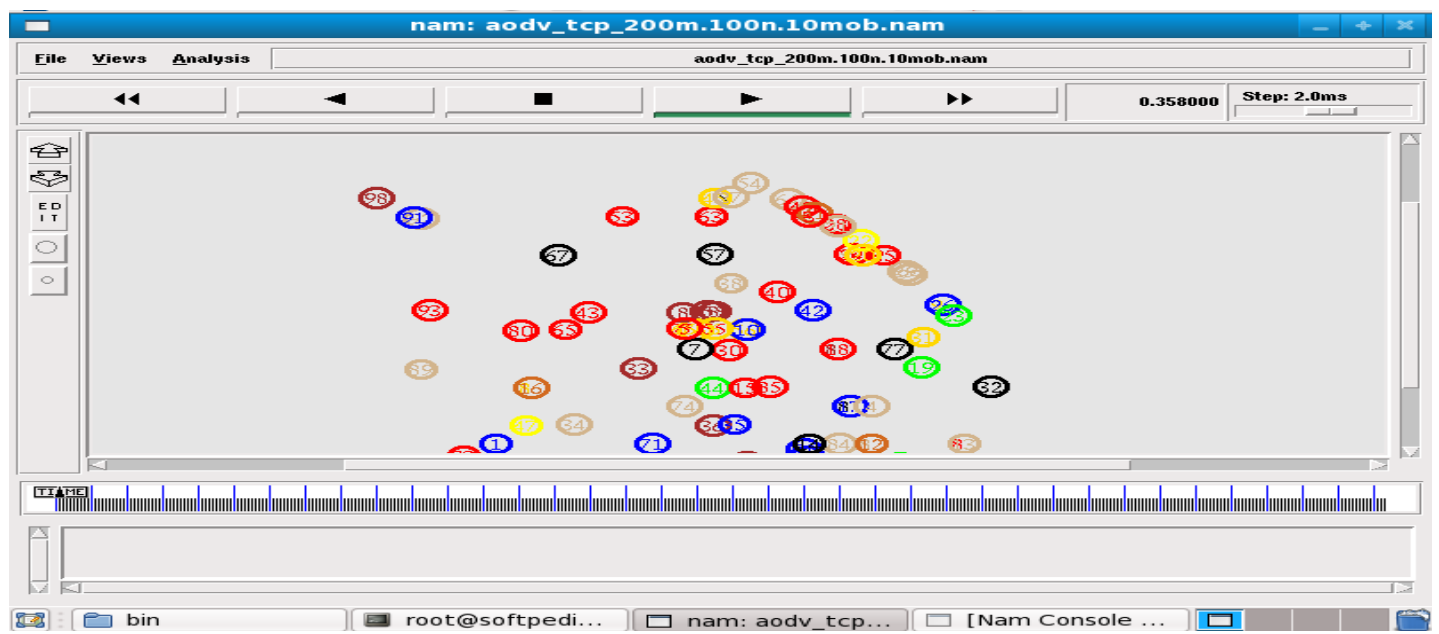

Fig. 2: Initial Positioning of 100 Nodes. 


\subsection{Network Survivability}

AODV with TCP shows more Network Survival Time than the AODV with UDP during the simulation. Figure 3 shows that for 75 nodes at $10 \mathrm{~m} / \mathrm{s}$ mobility speed and $20 \mathrm{~m}$ transmission range network will survive most. So this is the best combination for 75 nodes. Figure 4 shows that survival time of the network is most when mobility speed in $20 \mathrm{~m} / \mathrm{s}$ and transmission range is $300 \mathrm{~m}$ for 75 nodes. Results also shows that at lower transmission ranges and network survivability time is less and keeps on increasing with the increment in transmission range. Figure 5 shows the performance analysis of AODV on mobility speed 30 respectively. Result shows that the network will survive most when transmission range is $400 \mathrm{~m} \&$ mobility speed is $30 \mathrm{~m}$ for AODV with 75 nodes. For all the mobility speed \& Transmission ranges performance of TCP is better than UDP

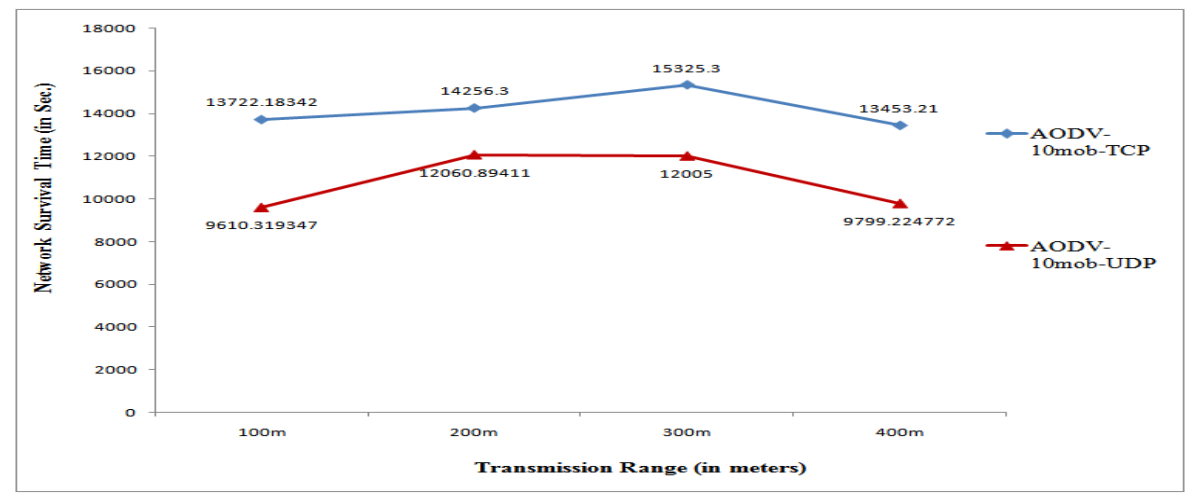

Fig. 3: Impact of Varying Transmission Range on Network Survivability for 75 nodes at 10 mobility speed with TCP \& UDP

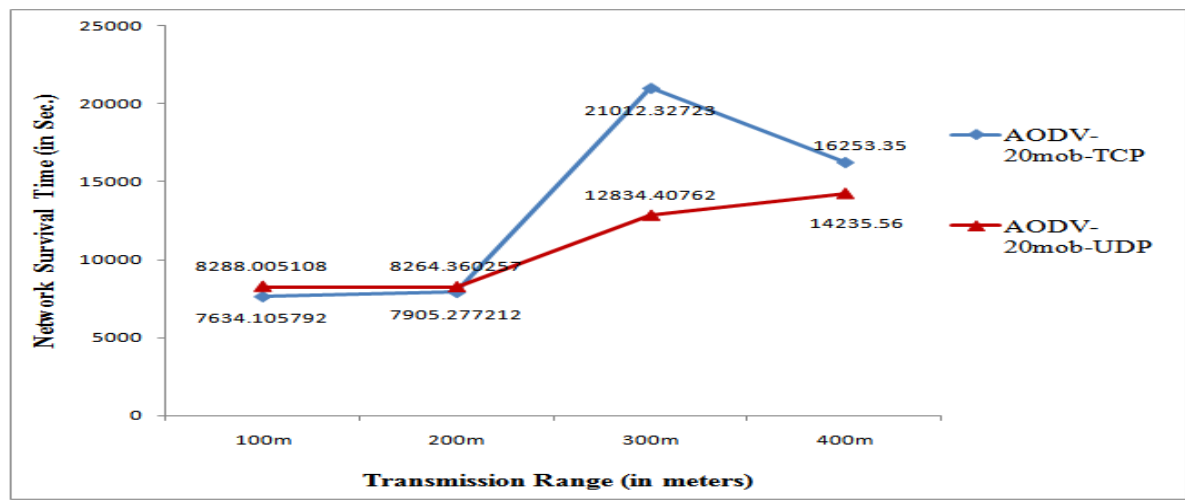

Fig. 4: Impact of Varying Transmission Range on Network Survivability for 75 nodes at 20 mobility speed with TCP \& UDP

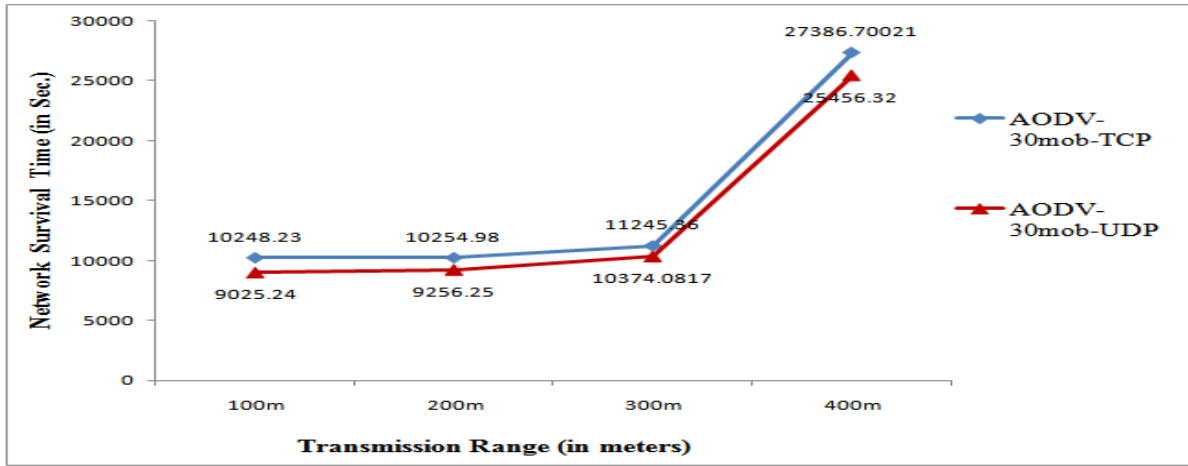

Fig. 5: Impact of Varying Transmission Range on Network Survivability for 75 nodes at 30 mobility speed with TCP \& UDP 
Figure 6-8 shows the performance of AODV network with 10,20\&30 mobility speeds respectively with 100 nodes. As the performance of 75 nodes, TCP performs better than UDP with 100 nodes too. AODV best performs when mobility speed is 20 \& Transmission range is $400 \mathrm{~m}$.

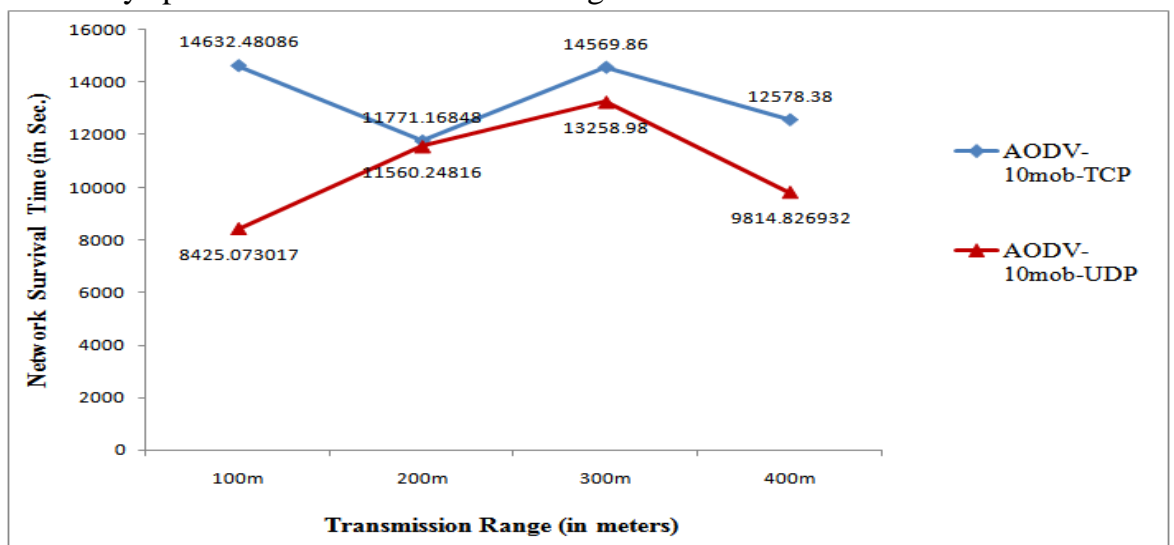

Fig. 6: Impact of Varying Transmission Range on Network Survivability for 100 nodes at 10 mobility speed with TCP \& UDP

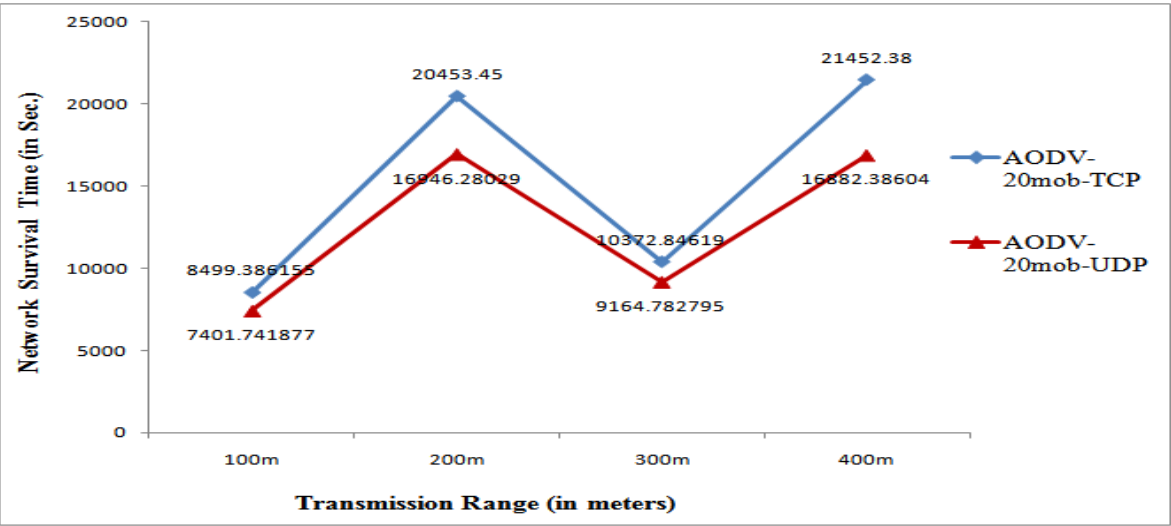

Fig. 7: Impact of Varying Transmission Range on Network Survivability for 100nodes at 20 mobility speed with TCP \& UDP

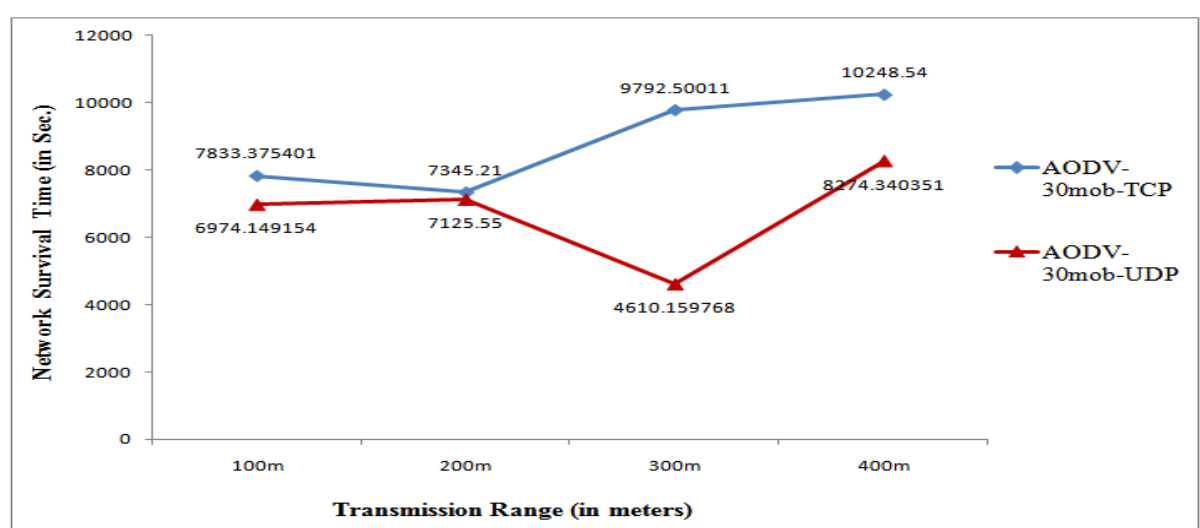

Fig. 8: Impact of Varying Transmission Range on Network Survivability for 100 nodes at 30 mobility speed with TCP \& UDP

Figure 9-10 shows the network survivability with respect to mobility speeds with transmission range $400 \mathrm{~m} \& 500 \mathrm{~m}$ respectively. Results shows the decline transmission trends with increase in mobility speeds with all the transmission ranges with 75 nodes 


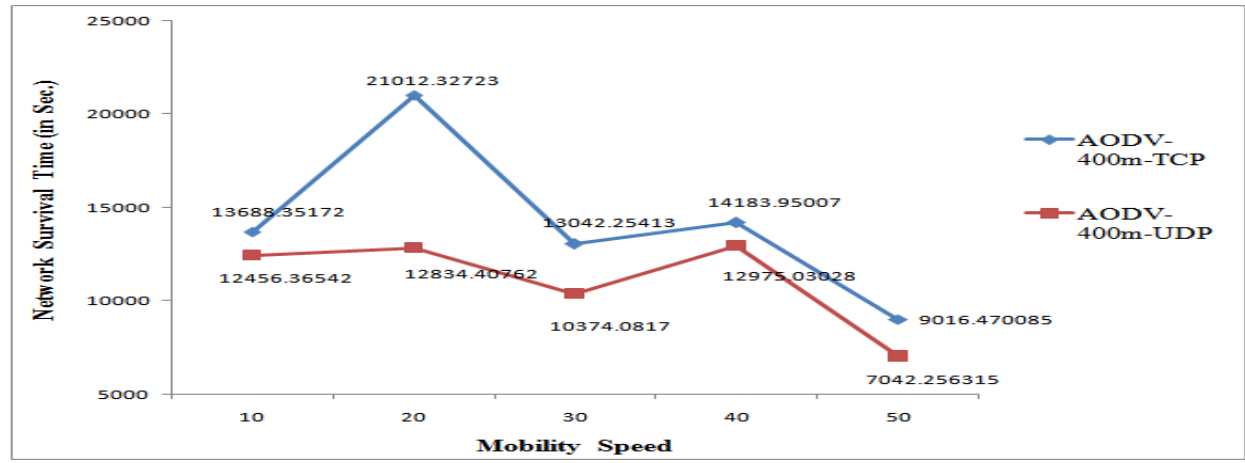

Fig. 9: Impact of Varying Mobility Speed on the Network Survivability for 75 nodes at 400m Transmission Range

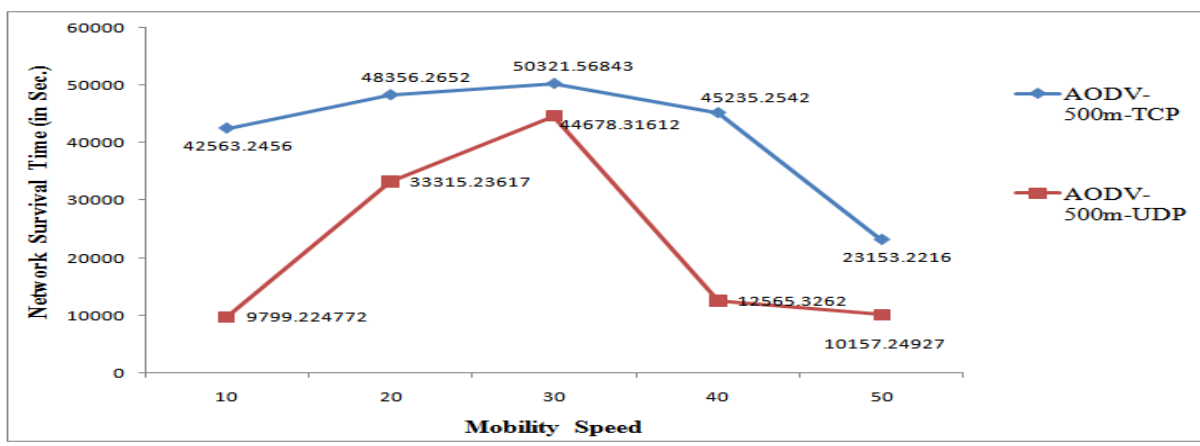

Fig. 10: Impact of Varying Mobility Speed on the Network Survivability for 75 nodes at 500m Transmission Range

Figure 11-12 shows the performance of AODV with nodes on the basis of mobility speed. Same as 75 nodes network, 100 nodes network also shows the declined performance with increase in mobility speeds

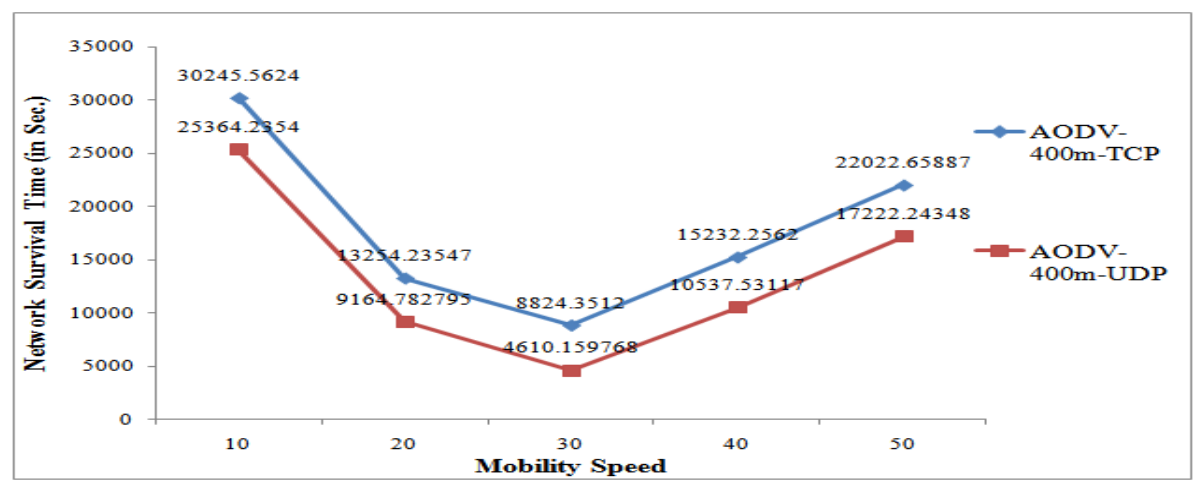

Fig. 11: Impact of Varying Mobility Speed on the Network Survivability for 100 nodes at 400m Transmission Range

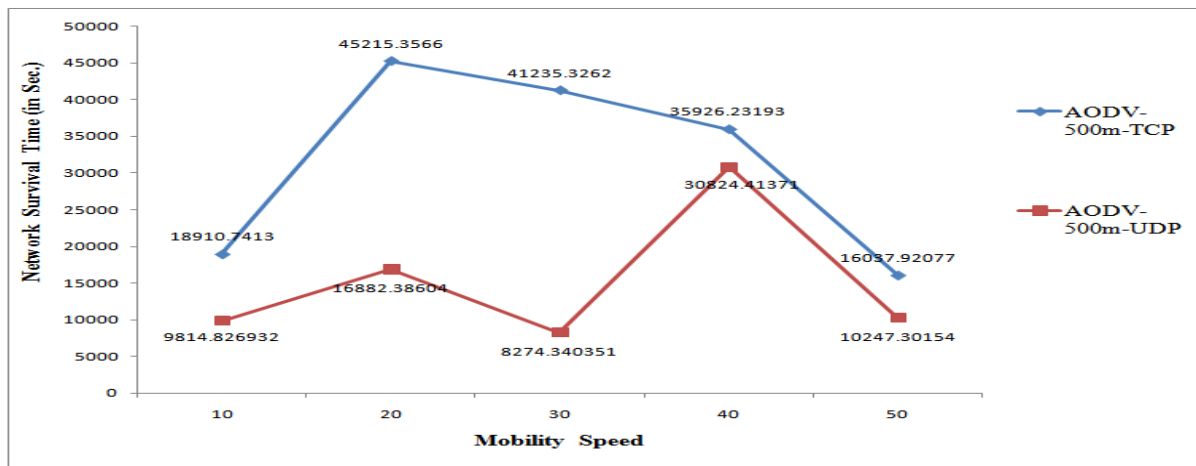

Fig. 12: Impact of Varying Mobility Speed on the Network Survivability for 100 nodes at $500 \mathrm{~m}$ Transmission Range 


\section{CONCLUSION}

The transmission range, mobility and different number of nodes as a system parameter affects the overall energy consumption and performance of MANET. The performance of AODV routing protocol shows some differences by varying transmission range, mobility speed and number of nodes. From our experimental analysis it is concluded that AODV has maximum network survival time with lower mobility speed and lowest network survival time with highest mobility speed. AODV is best when transmission range is $400 \mathrm{~m}$ with $30 \mathrm{~m} / \mathrm{s}$ mobility speed. The AODV protocol with variation in transmission range and mobility performed better with TCP as compared to UDP. It is also observed that the performance of AODV is better with 75 nodes network rather than 100 nodes so in bigger networks network will survive lesser. These results can be used to determine the proper radio transmission range in different mobility speed environments for the reactive routing protocol AODV in MANET without degrading a system performance.

\section{REFERENCES}

[1] Amruta Kodole and P. M. Agarkar, A Survey Of Routing Protocols In Mobile Ad Hoc Networks, Multidisciplinary Journal of Research in Engineering and Technology, 2(1), 2015, pp. 336-341.

[2] Mostafa Rajabzadeh, Arash Mazidi and Mehdi Rajabzadeh, SG-AODV: Smart and Goal Based AODV for Routing in Mobile Ad hoc Networks, International Journal of Advanced Research in Computer Science and Software Engineering, 5( 1), 2015.

[3] T. D. Lagkas, A. Lamproudi, P. Sarigiannidis and C. Skianis, The impact of mobility patterns on the efficiency of data forwarding in MANETs, in 2015 IEEE International Conference on Communications (ICC), London, DOI: 10.1109/ICC.2015.7249284, pp. 6037 6042, 8-12 June 2015.

[4] N. Sarmah, Y. Yang, H. Sharif and Y. Qian, Performance analysis of MANET routing protocols by varying mobility, speed and network load, in 9th International Conference on Signal Processing and Communication Systems (ICSPCS), Cairns, QLD, DOI: 10.1109/ICSPCS.2015.7391749, pp. 1 - 6, 14-16 Dec. 2015

[5] D. Dugaev, S. Zinov, E. Siemens and V. Shuvalov, "A survey and performance evaluation of ad-hoc multi-hop routing protocols for static outdoor networks", in International Siberian Conference on Control and Communications (SIBCON), Omsk, DOI: 10.1109/SIBCON.2015.7147048, pp. 1 - 11, 21-23 May 2015.

[6] S. K. Khatri and M. Dixit, Reducing Route discovery latency in MANETs using ACO, in 4th International Conference on Reliability, Infocom Technologies and Optimization (ICRITO) (Trends and Future Directions), Noida, DOI: 10.1109/ICRITO.2015.7359298, pp. $1-5,2-4$ Sept. 2015.

[7] C. J. Hwang, A. Kush and Ruchika, Performance evaluation of manet using quality of service metrics, in Fifth International Conference on Innovative Computing Technology (INTECH), Galcia, DOI: 10.1109/INTECH.2015.7173483, pp. 130 135, 20-22 May 2015.

[8] S. N. Mane, N. V. Mane and D. G. Khairnar, "Performance of mobile node between different MANET with Mobile IP", in International Conference on Industrial Instrumentation and Control (ICIC), Pune, DOI: 10.1109/IIC.2015.7151017, pp. 1662 1664, 28-30 May 2015.

[9] B. Bansal, M. R. Tripathy, D. Goyal and M. Goyal, Improved Routing Protocol for MANET, in Fifth International Conference on Advanced Computing \& Communication Technologies (ACCT), Haryana, DOI: 10.1109/ACCT.2015.108, pp. 340 - 346, 21-22 Feb. 2015.

[10] Ming-Yang Su and Chih-Wei Yang, A resilient routing approach for Mobile Ad Hoc Networks, in International Conference on High Performance Computing \& Simulation (HPCS), Amsterdam, DOI: 10.1109/HPCSim.2015.7237102, pp. 617 - 622, 20-24 July 2015.

[11] P. Thakur and A. Ganpati, Cluster based route discovery technique for routing protocol in MANET, in International Conference on Green Computing and Internet of Things (ICGCIoT), Noida, DOI: 10.1109/ICGCIoT.2015.7380539, pp. 622 - 626, 8-10 Oct. 2015.

[12] K. Matsuo, T. Oda, D. Elmazi, S. Sakamoto and L. Barolli, Performance Evaluation of AODV, OLSR and HWMP Protocols in AdHoc Networks and MANET Scenarios, Blumenau, DOI: 10.1109/IMIS.2015.7, pp. 15 - 21, 8-10 July 2015.

[13] B. R. Hanji and R. Shettar, Improved AODV with restricted route discovery area, in International Conference on Computer Communication and Informatics (ICCCI), Coimbatore, DOI: 10.1109/ICCCI.2015.7218065, pp. 1 - 6, 8-10 Jan. 2015.

[14] M. Gupta and S. Kumar, Performance Evaluation of DSR, AODV and DSDV Routing Protocol for Wireless Adhoc Network, in IEEE International Conference on Computational Intelligence \& Communication Technology (CICT), Ghaziabad, DOI: 10.1109/CICT.2015.95, pp. 416 - 421, 13-14 Feb. 2015.

[15] T. K. Halder, C. Chowdhury and S. Neogy, Power Aware AODV Routing Protocol for MANET, in Fourth International Conference on Advances in Computing and Communications (ICACC), Cochin, DOI:10.1109/ICACC.2014.84, pp. 331 - 334, 27-29 Aug. 2014

[16] S. Gupta and A. Mathur, Enhanced Flooding Scheme for AODV Routing Protocol in Mobile Ad Hoc Networks, in International Conference on Electronic Systems, Signal Processing and Computing Technologies (ICESC), Nagpur, DOI: 10.1109/ICESC.2014.60, pp. 316 - 321, 9-11 Jan. 2014

[17] B. Sakeena, R. Eklarker, V. V. Kohir and V. D. Mytri, QoS aware routing protocol to improve route maintenance in Mobile AdHoc Networks, in International Conference on Emerging Trends in Communication, Control, Signal Processing \& Computing Applications (C2SPCA), Bangalore, DOI: 10.1109/C2SPCA.2013.6749384, pp. 1-5, 10-11 Oct. 2013.

[18] V. Sharma, H. Singh and M. Kaur, Node-Mobility Sway in IEEE 802.11g MANET, in Third International Conference on Advanced Computing and Communication Technologies (ACCT), Rohtak, $\quad$ DOI: 10.1109/ACCT.2013.64, pp. 261 - 266, 6-7 April 2013.

[19] U. R. Bhatt, P. Jain and R. Upadhyay, Enhanced AODV - An energy efficient routing protocol for MANET, in International Conference on Engineering (NUiCONE), Ahmedabad, DOI: 10.1109/NUiCONE.2013.6780114, pp. 1-4, 28-30 Nov. 2013

[20] P. Srinivasan And P. Kamalakkannan, Enhancing route maintenance in RSEA- AODV for mobile ad hoc networks, in 7th International Conference on Intelligent Systems and Control (ISCO), Coimbatore, DOI: 10.1109/ISCO.2013.6481199, pp. 464 - 469, 4-5 Jan. 2013 
[21] Nadia Qasim, Fatin Said and Hamid Aghvami, Mobile Ad Hoc Networks Simulations Using Routing Protocols for Performance Comparisons, Proceedings of the World Congress on Engineering, London, U.K, Vol. 1, pp. 1-5, July 2-4, 2008.

[22] Rajneesh Gujral and Anil Kapil, Secure QoS Enabled On-Demand Link-State Multipath Routing in MANETs, Proceeding of BAIP 2010, SPRINGER LNCS-CCIS, Trivandrum, Kerala, India, pp. 250-257, March 26-27, 2010.

[23] Rajneesh Kumar Gujral, Jitender Grover and Anjali, An Analysis of Network Survivability with Variable Transmission Range and Mobility on AODV over MANET, TECHNIA-International Journal of Computing Science and Communication Technologies, 5(2), 2013, 870-878.

[24] J. Gomez, Energy-Efficient Routing and Control Mechanisms for Wireless Ad Hoc Networks, Ph.D. Thesis, Columbia University, NewYork, December 2002.

[25] G. Rajgopal, K. Manikandan , N.Sivakumar, QoS Routing using Energy Parameter in Mobile Ad Hoc Network, International Journal of Computer Applications, 22(4), 2011, 11-17.

[26] P. Vijayalakshmi, V. Saravanan, P. Ranjit Jeba Thangiah and J. Abraham Dinakaran, Energy-Aware Performance Metric for AODV and DSDV Routing Protocols in Mobile Ad-Hoc Networks, International Journal of Computer Science Issues (IJCSI), 8(4), 2011, 118-123.

[27] Chi Ma and Yuanyuan Yang, A Battery-Aware Scheme for Routing in Wireless Ad Hoc Networks, IEEE Transactions on Vehicular Technology, Vol. 60 (8), pp. 3919-3932, October 2011.

[28] S. Chettibi and M. Benmohamed, A Multipath Energy-Aware On demand Source Routing Protocol for Mobile Ad-Hoc Networks, Proceedings of CoRR,2009.

[29] P. Arivubrakan, V.R. Sarma Dhulipala, QoS Enhancement by varying Transmission Range in Wireless Ad-hoc Networks, International Journal of Computer Applications, 37(9), 2012, 1-4.

[30] Juan Carlos Cano and Pietro Manzoni, A Performance Comparison of Energy Consumption for Mobile Ad Hoc Network Routing Protocols, Proceeding of 8th International Symposium on Modeling, Analysis and Simulation of Computer \& Telecommunication System, pp. 57-62, 2000.

[31] N. Javaid, M. Yousaf, A. Ahmad, A. Naveed, K. Djouani, Evaluating Impact of Mobility on Wireless Routing Protocols, IEEE Symposium on Wireless Technology and Applications (ISWTA), Langkawi, Malaysia, pp. 84-89, Sept. 25-28, 2011.

[32] A. Rahman and Z. Zukarnain,, Performance Comparison of AODV, DSDV and I-DSDV Routing Protocols in Mobile Ad-hoc Networks, European Journal of Scientific Research, 31(4), 2009, 566-576.

[33] N.Usop, A.Abdullah and A.Abidin, Performance Evaluation of AODV, DSDV and DSR routing Protocol in Grid Environment, International Journal of Computer and Network Security, 9(7), 2009, 261-268.

[34] Harminder S. Bindra, Sunil K. Maakar and A.L.Sangal, Performance Evaluation of Two Reactive Routing Protocols of MANET using Group Mobility Model, International Journal of Computer Science Issues (IJCSI), 7(10), 2010, 38-43.

[35] F. Anwar, M. Azad, M. Rahman and M. Uddin, Performance Analysis of Ad-hoc Routing Protocols in Mobile WiMAX Environment, IAENG International Journal of Computer Science, 35(3), 2008, 353-359.

[36] Vivek Thaper, Bindyia Jain and Varsha Sahni, Performance Analysis of Ad Hoc Routing Protocols Using Random Waypoint Mobility Model in Wireless Sensor Networks, International Journal on Computer Science and Engineering (IJCSE), 2011, 3059-3063.

[37] A. Boomarani Malany, V.R. Sarma Dhulipala and R. M. Chandrasekaran, Throughput and Delay Comparison of MANET Routing Protocols, International Journal of Open Problems Compt. Math, 2(3), 2009, 461-468.

[38] Rajneesh Kumar Gujral, and Manpreet Singh, Performance Analysis of Ad hoc Routing Protocols for Voice Communication Support over Hybrid MANETs, International Journal of Computer Applications (IJCA), 22(3), 2011, 42-48.

[39] Bhavyesh Divecha, Ajith Abraham, Crina Grosan and Sugata Sanyal, Impact of Node Mobility on MANET Routing Protocols Models, Journal of Digital Information Management, 5(1), 2007, 19-23.

[40] Jitender Grover, Jony and Jitender, Impact of Connectionless \& Connection Oriented Communication with Variable Transmission Range and Mobility on Routing Protocols Over Manets, International Journal of Engineering Research and Applications, 3( 6), 2013, 918-926.

[41] Anurag Malik, Shivanshu Rastogi and Sajendra Kumar, Performance Analysis of Routing Protocol in Mobile Ad Hoc Network using NS-2, MIT International Journal of Computer Science \& Information Technology, 11, 2011, 47-50.

[42] Jitender Grover and Parneet Kaur, Impact of Variable Transmission Range and Scalability With Respect To Mobility and Zone Size On Zone Routing Protocol Over Manets, International Journal of Engineering Research and Application, 3(5), 2013, 1639-1646.

[43] David .B Johnson, David. A. Maltz, and Josh Broch, "Dynamic Source Routing protocol for Multihop Wireless Ad Hoc Networks", In Ad Hoc Networking, edited by Charles E. Perkins Addison-Wesley, Chapter 5, pp. 139-172, 2001.

[44] Rajneesh Gujral, Jitender Grover, Anjali and Sanjeev Rana, "Impact of Transmission Range and Mobility on Routing Protocols over Ad hoc Networks", IEEE International Conference on Computing Sciences, LPU, Phagwara, Punjab, ISBN: 978-1-4673-2647-6, DOI 10.1109/ICCS.2012.41, pp. 201-206, 2012. 